\section{ANAESTHETIST}

Cambridge Memorial Hospital is seeking the services of an Ontario licensed, Canadian certified Anaesthetist. This community of 93,000 residents, with 353 bed accredited modem hospital and 9,000 surgical suite visits per year, is served by a broad range of specialists, excluding Neuro and C.V. Surgery. The Anaesthetic Department is well equipped with stateof-the-art equipment, and has five certified Anaesthetists. This vacancy is as a result of the retirement of one.

Cambridge is in the heart of Southwestem Ontario, within one hour's drive of Toronto, London, and Hamilton, and provides a high standard of living, including excellent social, recreational and educational facilities.

For more information, contact Dr. S.B. Goel, Chief, Department of Anaesthesia (519) 621-9842, or send your application, in writing, to:

Secretary, Anaesthetist

Search Committee,

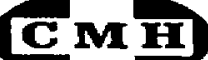

Cambridge Memorial Hospital,

700 Coronation Blyd.,

Cambridge, ON. N1R 3G2

\section{ANAESTHETIST}

\section{Ross Memorial Hospital}

Position available immediately for an anaesthetist who is certified, eligible for certification or a G.P.J Anaesthetist to join four anaesthetists in this 206bed community hospital in Lindsay. Enjoy quality of life, recreational haven, excellent schools, in an active community 90 minutes from Toronto.

Applicants are requested to direct resumes or inquiries to:

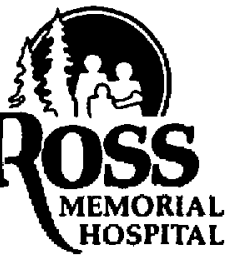

Ross Memorial Hospital 10 Angeline St. North

Lindsay, Ont. K9V 4M8

Dr. E. Ready

Assistant Chief of

Anaesthesia

Tel. (705) 324-3221, or

Dr. R.D. Drury

Chief of Staff

Tel. (705) 324-6111

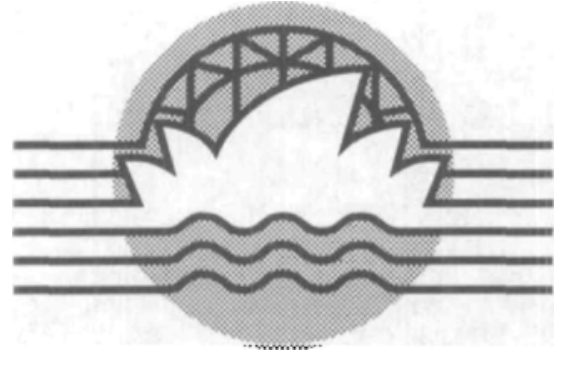

\title{
11th World Congress of Anaesthesiologists Sydney, Australia 14-20 April 1996
}

\section{Call for Abstracts}

The closing date for Abstracts of Scientific Communications for presentation at the 11 th World Congress will be September 30, 1995.

Abstract forms with instructions for authors will be available in June 1995 and will be distributed together with the Registration Brochure from your National Society.

\section{"Anaesthesiology - Coming together 150 years on"}

For further information please contact:

11 th World Congress of Anaesthesiologists

GPO Box 2609, Sydney NSW 2001, Australia

Tel: (61 2) 2411478 Fax: (61 2) 2513552 